\title{
Diabetes in sub-Saharan Africa - from policy to practice to progress: targeting the existing gaps for future care for diabetes
}

This article was published in the following Dove Press journal:

Diabetes, Metabolic Syndrome and Obesity:Targets and Therapy

22 June 2017

Number of times this article has been viewed

\author{
Sonak D Pastakia' \\ Chelsea R Pekny' \\ Simon M Manyara ${ }^{2}$ \\ Lydia Fischer ${ }^{3}$
}

'Department of Pharmacy Practice, Purdue University College of Pharmacy, Indianapolis, IN, USA; ${ }^{2}$ Department of Pharmacy, Moi Teaching and Referral Hospital, Eldoret, Kenya; ${ }^{3}$ Department of Pediatrics, Indiana University School of Medicine, Indianapolis, IN, USA
Correspondence: Sonak D Pastakia Indiana Institute for Global Health, PO Box 5760, Eldoret 30100, Kenya Tel +254729027569 Email spastaki@gmail.com
Abstract: The global prevalence and impact of diabetes has increased dramatically, particularly in sub-Saharan Africa. This region faces unique challenges in combating the disease including lack of funding for noncommunicable diseases, lack of availability of studies and guidelines specific to the population, lack of availability of medications, differences in urban and rural patients, and inequity between public and private sector health care. Because of these challenges, diabetes has a greater impact on morbidity and mortality related to the disease in sub-Saharan Africa than any other region in the world. In order to address these unacceptably poor trends, contextualized strategies for the prevention, identification, management, and financing of diabetes care within this population must be developed. This narrative review provides insights into the policy landscape, epidemiology, pathophysiology, care protocols, medication availability, and health care systems to give readers a comprehensive summary of many factors in these domains as they pertain to diabetes in sub-Saharan Africa. In addition to providing a review of the current evidence available in these domains, potential solutions to address the major gaps in care will be proposed to reverse the negative trends seen with diabetes in sub-Saharan Africa.

Keywords: outcomes, protocols, medication access, pathophysiology, epidemiology, health care systems

\section{Introduction}

Diabetes is a disease that wreaks havoc when health care systems are not aligned and consistently functioning. ${ }^{1}$ This is clearly illustrated by the suboptimal results seen in individual patients and patient cohorts in the relatively few studies available from sub-Saharan Africa. ${ }^{2-4}$ With inadequate spending to bolster health care systems to manage chronic diseases, there have been only minimal population-level gains in chronic disease health outcomes, especially with regard to diabetes. ${ }^{2,5}$ To improve care for diabetes populations in sub-Saharan Africa, a comprehensive evaluation of the policy landscape, epidemiology, pathophysiology, care protocols, medication availability, and health care systems must be considered (Figure 1). With the dramatic differences between care in high-income countries (HICs) versus low- and middle-income countries (LMIC), rural versus urban settings, and private versus public sector systems, special considerations for each need to be made to maximize health care benefits. This review briefly touches upon these key differences and also provides overarching suggestions to sustainably address the identified gaps in care.

\section{Methods}

This nonsystematic, narrative review utilizes the limited amount of currently available primary information from a literature search by using PubMed search criteria 


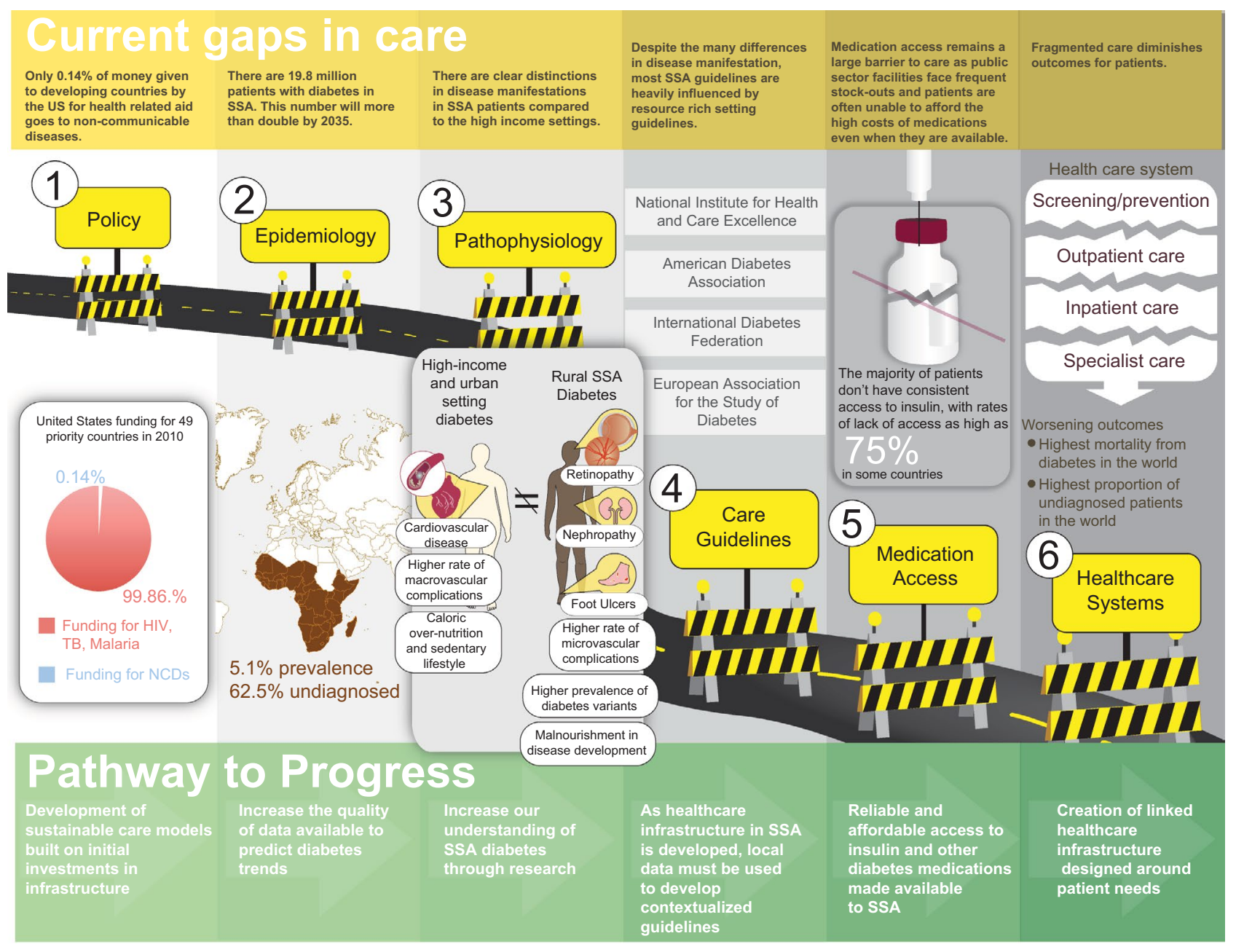

Figure I Current gaps in diabetes care in sub-Saharan Africa and potential pathways to progress.

Abbreviations: HIV, human immunodeficiency virus; TB, tuberculosis; NCD, noncommunicable disease; SSA, sub-Saharan Africa.

including "diabetes and sub-Saharan Africa" and other available information from Internet searches of respected and reputable institutions including the International Diabetes Federation (IDF), the World Health Organization (WHO), the World Diabetes Foundation, governmental institutions, and other institutions as cited. Where data and information are unavailable, the authors have noted a lack of available information and provided informed opinions and accounts from personal experience from implementing diabetes care over the past decade in Western Kenya. This narrative method has brought available information into a comprehensive assessment of the gaps and barriers that hinder progress in diabetes care in sub-Saharan Africa and identifies potential pathways to progress.

\section{Policy}

\section{Funding}

Although most policy initiatives continue to focus on the growing burden of diabetes in HICs, it is important to note that $77 \%$ of patients with diabetes reside in LMICs. ${ }^{2,5}$ The importance of this rapid escalation of diabetes, especially in sub-Saharan Africa, cannot be overstated as it threatens to destabilize already fragile economies still reeling from infectious disease epidemics, including ebola, human immunodeficiency virus (HIV), tuberculosis (TB), and malaria.$^{6-9}$ Despite the disproportionate burden of diabetes and other noncommunicable diseases (NCDs) in LMICs, external and internal funding for health care needs continues to focus on communicable diseases while neglecting the needs of the large populations experiencing excess morbidity and mortality from NCDs. For example, in 2010, the United States committed only $\$ 10.8$ million $(0.14 \%)$ of its $\$ 8$ billion in global health funding to NCDs. ${ }^{10}$ This trend of limited funding for NCDs is further illustrated by the statistics on the investments made by the US government in the 49 priority LMICs that it provides the highest amount of global health investment to. In terms of disability-adjusted life years (DALYs) from 2010, the US government spent 
\$44.17 for each DALY lost to HIV/AIDS, \$4.21 per DALY lost to malaria, $\$ 1.82$ per DALY lost to TB, but only $\$ 0.02$ per DALY lost to NCDs. ${ }^{10}$ These disturbing trends of global neglect toward NCDs continue despite the commitments and statements made during the high-level meeting on NCDs at the United Nations in 2011. ${ }^{11}$ Although several action plans have been developed, the initial investments required to make them a reality in sub-Saharan Africa are yet to be realized. ${ }^{10,11}$

The lack of global commitment is further complicated by the relatively limited in-country funding that sub-Saharan African countries dedicate to health compared with the rest of the world. In 2014, sub-Saharan African countries spent $5.5 \%$ of their gross domestic product (GDP) on health (private and public sector) compared with the $12.4 \%$ that the Organization for Economic Cooperation and Development countries spend annually on health. ${ }^{12}$ Further examination of data from the World Bank in 2014 reveals that sub-Saharan African countries funding for public sector health care is only $42.6 \%$ of the total health care spending or $2.3 \%$ of the total GDP. Average per capita spending is $\$ 98$ (US, 2014), despite the heavy reliance that populations in sub-Saharan
Africa have on public sector health care. ${ }^{10,12,13}$ In comparison, public sector health care funding for the European Union, Latin America and Caribbean, and Middle East and North Africa are $7.8 \%, 3.7 \%$, and $3.2 \%$ of the total GDP, respectively, with per capita spending amounting to $\$ 3613$, $\$ 714$, and $\$ 433$ (US, 2014), respectively. ${ }^{12,13}$

With the much lower GDP typically found in sub-Saharan Africa, the absolute amount of funding for the health care needs of all parts of this vast region continues to lag far behind other LMICs as seen in Figure 2. ${ }^{10}$

As a result of the existing high burden of infectious diseases and NCDs, countries in sub-Saharan Africa have also typically prioritized communicable diseases over NCDs by committing $\geq 80 \%$ of their health budget to communicable diseases over the past two decades. ${ }^{14}$

\section{Infrastructure}

A more in-depth consideration of the policy and funding challenges amidst competing health care priorities paints an even bleaker picture around diabetes as the multiorgan impact of the disease, and high costs of prevention and management make it an even more challenging burden to

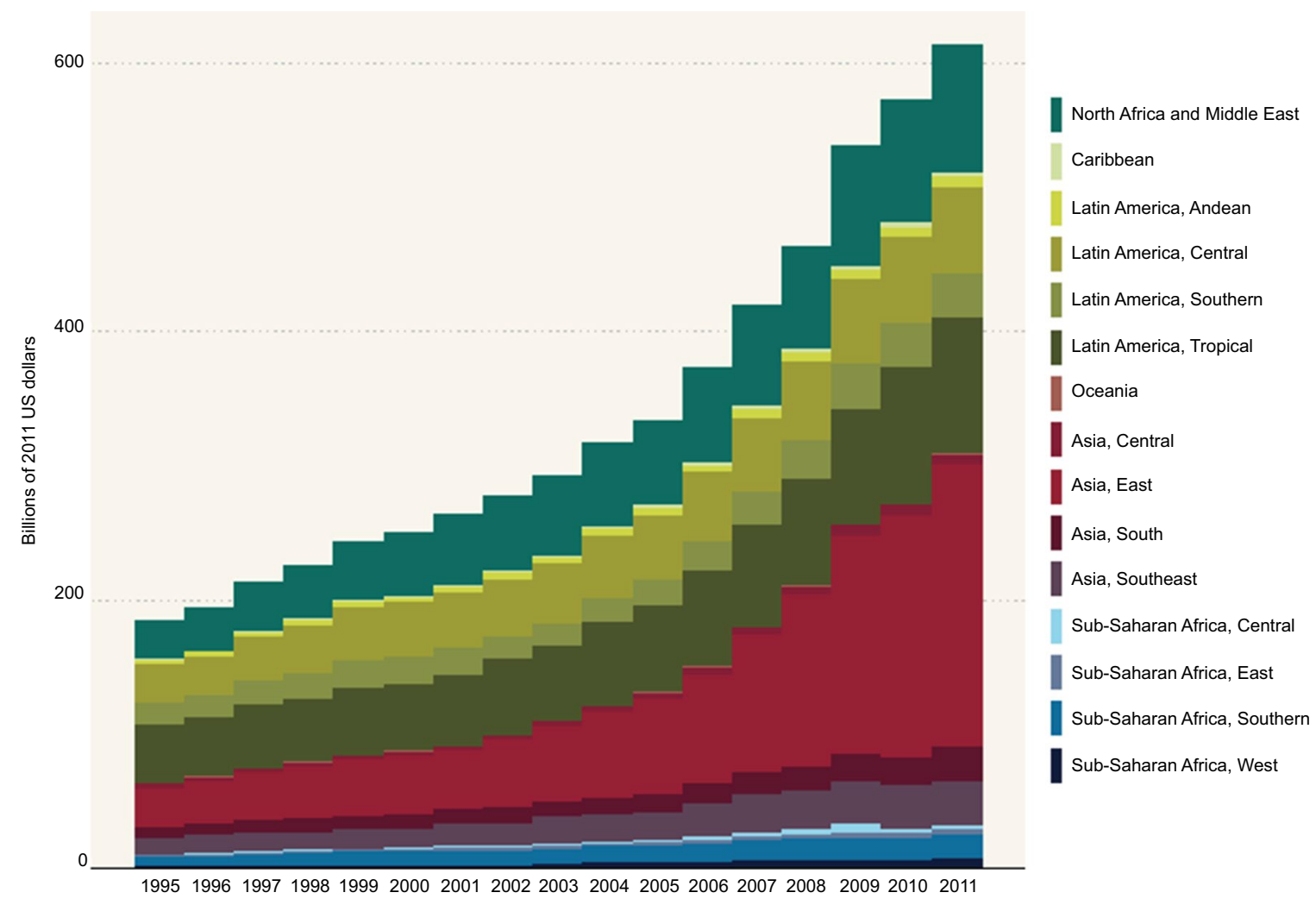

Figure 2 Low- and middle-income country government health spending by region.

Notes: Reproduced from Independent Task Force on Noncommunicable Diseases: The Emerging Global Health Crisis: Noncommunicable Diseases in Low- and MiddleIncome Countries, Task Force Report No. 72. New York: Council on Foreign Relations Press; 2014. Copyright 2014 by the Council on Foreign Relations. Reprinted with permission. ${ }^{10}$ Figure data source: Institute for Health Metrics and Evaluation (IHME). Financing Global Health Visualization. Seattle, WA: IHME, University of Washington, 2016. Available from http://vizhub.healthdata.org/fgh/. (Accessed September I, 20I5). Copyright $\odot 2014$ by the Council on Foreign Relations $®$, Inc. All rights reserved. ${ }^{102}$ 
address. At the same time, while considering investments in diabetes care infrastructure, these investments can be viewed as investments in all NCDs. The crosscutting infrastructure required to comprehensively manage diabetes will benefit the entire health systems and will simultaneously address cardiovascular, ocular, mental health, renal, and neurological disorders. Manifestations and frequencies of these diabetesassociated comorbidities in sub-Saharan Africa are discussed in the "Pathophysiology" section.

\section{Prevention}

Although the immediate needs of the population already facing diabetes are dire, there exists an equally important need to introduce policy designed to encourage the creation of nutritious food environments and avoid emerging food environments that are being flooded with obesogenic/diabetogenic foods (sugar sweetened beverages, highly processed foods, etc).$^{5,15,16}$ This nutrition transition is fueling the dramatic rise in diabetes prevalence in urban areas that are shifting toward a more western, sedentary style of life. Although this nutrition and lifestyle transition does not seem to have reached many rural sub-Saharan African settings yet, the extension of this trend is inevitable as the economic growth of sub-Saharan Africa continues to increase. In addition to a nutritious food environment, education about healthy eating and physical activity needs to be implemented at all levels, targeting children and adults as well as urban and rural markets. To identify the unique prevention strategies needed for rural areas, contextualized, culturally adapted research needs to be supported to investigate the dietary patterns that may be increasing the risk for diabetes.

\section{Path to progress}

It is unlikely that a concerted funding effort will become available for NCDs, including diabetes, similar to that which was seen for HIV, TB, and malaria. In the face of this funding challenge, we are presented with a choice of allowing sub-Saharan African patients with diabetes to suffer unacceptably high levels of excess morbidity and mortality as we wait for outside funding sources, or we can develop sustainable strategies that address the policy-related issues that patients with diabetes in sub-Saharan Africa face. The second choice requires a multipronged and integrated approach, which includes prevention efforts focused on policy-based requirements for education about healthy lifestyles and disease prevention, creation of donor-independent health care systems that provide affordable access to high-quality diabetes services, and efforts to increase awareness among local governmental agencies responsible for domestic funding allocations.

\section{Epidemiology}

The prevalence of diabetes in sub-Saharan Africa, similar to trends being seen worldwide, is rapidly rising. ${ }^{2}$ The sub-Saharan African region is expected to see the largest percentage increase in the incidence of diabetes of any region in the world. In 2015, the IDF estimated that there were 14.2 million people with diabetes in sub-Saharan Africa. $^{2}$ This number is expected to increase to 34.2 million patients by $2040 .{ }^{2}$ Prevalence is highly varied between countries, with prevalence ranging from a low of $0.6 \%$ in Benin to a high of $18.2 \%$ in Réunion, off the coast of Madagascar. ${ }^{2}$ There is also great variability in rural versus urban prevalence with urban areas facing the brunt of the burden. The wide variation in diabetes prevalence can be explained partly due to regional differences in lifestyle and body mass index (BMI), as well as the great variability in the methods and locations of studies used to generate these estimates. ${ }^{17}$

Current knowledge of diabetes in sub-Saharan Africa is based largely on epidemiological data taken during sporadic, predominantly convenience based community testing initiatives and hospital data from patients who present with diabetes complications. There are few comprehensive surveys, and the wide variations in prevalence makes it difficult to have an accurate estimate of the impact of diabetes in the region. ${ }^{17}$ Type 2 diabetes is the predominant form of diabetes in sub-Saharan Africa, accounting for an estimated $85 \%-95 \%$ of cases. ${ }^{18}$ Type 1 diabetes and atypical variants of diabetes, including malnutrition-related and ketosis prone diabetes, account for 5\%-15\% of cases. ${ }^{3,17}$ A majority of patients with diabetes in sub-Saharan Africa are undiagnosed, with an estimated $62.5 \%$ of cases being undiagnosed in the region. ${ }^{2}$ Under diagnosis can be attributed to a lack of access to health care facilities, poorly trained health care providers, and lack of screening. Further compounding with these deficiencies is the anticipated increase in incidence and subsequent prevalence of diabetes that will accompany the rapid urbanization of sub-Saharan African populations. This will increase the proportion of the population who are exposed to the more diabetogenic sedentary lifestyle with calorie-rich diets typically seen with urbanization. ${ }^{3}$ This ongoing and projected shift in diet has resulted in populations consuming more calorically dense foods with increased fat and sugar and less fiber compared with the traditional diets of previous generations..$^{3,19,20}$ This shift is further ingrained among 
the cultural norms of the population as many sub-Saharan African cultures view being overweight or obese as a symbol of wealth and prosperity. ${ }^{21,22}$

With shifts in the lifestyles of urban populations, type 2 diabetes prevalence is $1.5-4$ times higher in urban settings compared with rural settings. ${ }^{4}$ This is further complicated by the rapid urbanization taking place in sub-Saharan African populations. In 2013, 37\% of the population lived in urban areas compared with only $10 \%-15 \%$ in $1950 .{ }^{23}$ By 2030 , this number is expected to be $50 \%$, making sub-Saharan Africa the fastest growing urban population in the world. ${ }^{23}$

In addition to changes in lifestyle and nutrition being common in sub-Saharan African populations and contributing to increases in diabetes prevalence, the likelihood of developing diabetes is also increased as the life expectancy in sub-Saharan Africa increases. ${ }^{24}$ As we continue to improve health care infrastructure and living conditions, there will be additional gains in life expectancy, which will continue to add to the incidence and prevalence of diabetes as the population ages. ${ }^{3}$ The specific projections for increased life expectancy vary across regions, but on average, the increase in life expectancy in Africa is expected to increase to 64 years by 2030 from 57 years in $2010 .^{23}$

The number of patients with type 1 diabetes in sub-Saharan Africa is low relative to the rest of the world..$^{2}$ In 2013, the number of children with type 1 diabetes from birth to 14 years of age was 39,100, the lowest in sub-Saharan Africa compared with other regions in the world, a prevalence of $\sim 0.009 \% .^{2}$ In comparison, the number of children from birth to 14 years of age with type 1 diabetes in Europe in 2013 was 129,400, a prevalence of $\sim 0.16 \%$. $^{2}$ Unfortunately, patients who have type 1 diabetes are not expected to survive more than a year after initial diagnosis in most parts of sub-Saharan Africa which are not well equipped with health care facilities and services. ${ }^{24}$ This unfortunate reality combined with limited diagnosis and poor data collection confounds the evaluation of comparative prevalence as the excess mortality and low rates of detection faced in sub-Saharan Africa continues to lead to preventable early deaths for thousands of juvenile cases of diabetes that reduce the prevalence estimates for type 1 diabetes. $^{24}$

Diabetes is particularly devastating in sub-Saharan Africa from both an economic and a health care standpoint. Diabetes in sub-Saharan Africa is associated with the highest rate of morbidity and mortality in the world, particularly in the population who are able to work. ${ }^{2}$ In sub-Saharan Africa in $2014,76.4 \%$ of deaths attributed to diabetes were in people aged $<60$ years. $^{2}$ The primary reasons for these high rates of morbidity and mortality are typically attributed to the late diagnosis and poor care that patients receive throughout the course of disease.

In addition, diabetes carries a twofold burden in subSaharan Africa because of the increased risk of infectious diseases such as HIV, TB, and pneumonia. ${ }^{25}$ This is of significant importance as the next epidemic of TB cases in LMICs are expected to be related to this increased prevalence of diabetes. Previous studies have shown that diabetes increases the risk of TB nearly threefold, and evidence also suggests that having TB may predispose individuals to developing diabetes. ${ }^{17,26}$ Furthermore, poor glycemic control in patients with diabetes has been associated with a higher risk for TB compared with patients with tightly controlled blood sugar. ${ }^{27}$ Although there has been recent progress in stabilizing the number of new cases of TB through improvements in access to HIV treatment, many of these gains could be reversed if the numbers of people with diabetes continue to grow as projected. ${ }^{27,28} \mathrm{HIV}$ and TB also contribute to the increase in diabetes cases seen in sub-Saharan Africa. TB infection, like other infections, can augment glucose tolerance in patients during infection, although it is unknown if this contributes significantly to the development of diabetes. ${ }^{26} \mathrm{HIV}$ and the antiretroviral medications used to suppress its replication are both associated with metabolic dysfunction and changes in insulin sensitivity, leading to metabolic syndrome and/or diabetes. ${ }^{26,29}$ In addition, patients who receive antiretroviral therapy live longer, which increases the risk of developing diabetes because of the previously described risks with advanced age and extended exposure to medications with metabolic side effects. ${ }^{29}$ In addition to these traditional risk factors for diabetes development, there is a growing interest in describing the role of chronic inflammation observed in HIV-infected patients in the development of diabetes as inflammation has been shown to be an independent risk factor for the development of diabetes. This is compounded by the findings that HIV-infected patients tend to have a higher degree of chronic inflammation than non-HIV-infected patients providing another potential source of risk for the development of diabetes. ${ }^{30}$

The preceding paragraphs describe the unique characteristics that are driving the increase in diabetes in sub-Saharan Africa. Unfortunately, patients with diabetes are prone to high rates of microvascular complications. Microvascular complications, and their associated estimates, that are commonly seen in sub-Saharan African settings include cataracts $(9 \%-16 \%),{ }^{31}$ retinopathy $(7 \%-63 \%),{ }^{32-39}$ neuropathy $(27 \%-66 \%),{ }^{40,41}$ microalbuminuria $(10 \%-83 \%),{ }^{33,42}$ and 
nephropathy (32\%-57\%). ${ }^{43,44}$ Although there is a great deal of variation in the quality and reliability of reporting these complications in different settings, these microvascular complications seem to have a much higher prevalence in patients from sub-Saharan Africa, especially in those who have had a longer course of disease and poor glycemic control. ${ }^{17,45-47}$ In contrast, patients in HICs experience relatively more macrovascular complications, such as cardiovascular disease, peripheral vascular disease, and stroke. In sub-Saharan African populations, these macrovascular complications are relatively rare despite a high prevalence of concomitant hypertension with diabetes. ${ }^{43,48}$

In addition to addressing these more commonly described diabetes-related complications, there needs to be a greater focus on addressing mental health conditions, such as depression, that often complicate care for patients with diabetes. Data from a rural diabetes specialty clinic in Kenya found that $21 \%$ of its patients reported depressive symptoms that were associated with worsened glycemic control compared with screen negative patients. Although mental health disorders are often neglected in LMICs, the development of infrastructure for NCDs like diabetes necessitates a renewed focus on addressing mental health disorders to maximize patient outcomes. ${ }^{49-51}$
Although the available epidemiological data on complications illustrate the differences between HIC and LMIC populations, there has been only limited investigation on the epidemiology of the different variants of diabetes that are more frequently found among sub-Saharan Africa populations. As health care systems continue to mature in sub-Saharan Africa, specific strategies for differentiating these variants must be developed to enhance the epidemiological understanding of these unique forms of diabetes. An enhanced epidemiological understanding would help to facilitate the development of variant-specific management approaches, which could address the underlying causes and nutritional deficits that lead to their development.

\section{Path to progress}

Health care systems must enhance the collection of data regarding diabetes to increase accuracy in predictions of changes in diabetes prevalence, complications, mortality, and presence of atypical variants. Through the integration of reliable data collection methods and efforts to increase access to reliable health care infrastructure, policy makers and health care systems will be equipped with the data and tracking capabilities needed to stave off the unprecedented projection of growth of patients afflicted by diabetes.

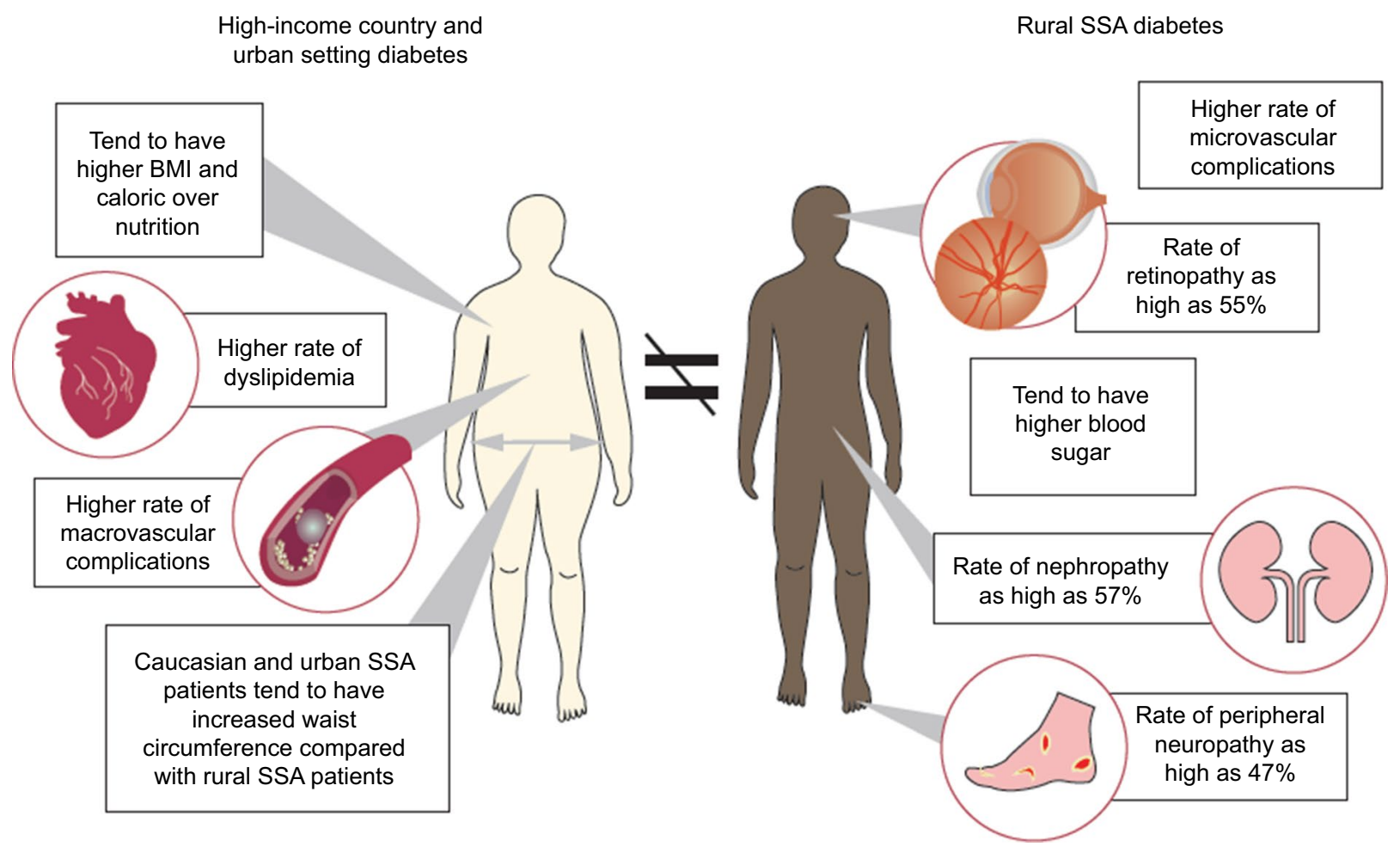

Figure 3 Differences in pathophysiological presentation of diabetes in HICs and urban setting diabetes compared with rural Sub-Saharan African diabetes. Abbreviations: HICs, high-income countries; BMI, body mass index; SSA, sub-Saharan Africa. 


\section{Pathophysiology}

The pathophysiology of type 1 and type 2 diabetes in subSaharan Africa, particularly type 2 diabetes and subtypes of type 2 diabetes, differs drastically from that of other regions. These differences are outlined in Figure 3.

Type 1 diabetes presentation in sub-Saharan Africa is generally later in life, with patients commonly being diagnosed in their 20s to 40 s and with more severe clinical presentations during diagnosis including diabetic ketoacidosis (DKA), hyperosmolar non-ketotic coma, and hypoglycemia than the typical presentation of type 1 diabetes in Caucasian patients. ${ }^{29}$ The differences between sub-Saharan African and Caucasian patients extend far beyond the clinical presentation. Autoimmunity is well documented in Caucasian patients with type 1 diabetes from HICs; with prevalence of autoinsulin antibodies, islet cell antibodies, and glutamic acid decarboxylase enzyme antibodies measured from $65 \%$ to $80 \%$ at presentation of disease. ${ }^{29}$ Although information about the presence of antibodies is limited, autoimmunity measured in type 1 diabetes patients from Tanzania and South Africa revealed a prevalence of islet cell antibodies ranging from $8 \%$ to $11 \%$ and a prevalence of glutamic acid decarboxylase enzyme antibody of $44 \% .^{29}$ These studies suggest that autoimmunity based on the markers identified among Caucasian populations may not play as much of a role in diabetes in sub-Saharan Africa. Likewise, genetic markers, such as HLA DR3/4, which are known to confer susceptibility to type 1 diabetes in Caucasians, have lower prevalence in type 1 diabetes patients in sub-Saharan Africa than in European populations. ${ }^{3,29}$ These findings highlight the gaps in our current knowledge about the genetics of diabetes in sub-Saharan Africa while also illustrating the marked differences in the genetic and immune-mediated underpinnings of the disease. ${ }^{3,29}$ The disease is usually characterized by severe hyperglycemia with or without ketosis and is well managed with appropriate insulin therapy; however, patients with poor access to health care often do not survive the initial severe hyperglycemia episode because of either ketosis or infection. $^{52}$

Recent investigation into the genetic variations in patients with diabetes from different parts of the world has provided additional insight to better understand the marked differences in diabetes pathophysiology between patients. Genetic variations and propensity for the development of disease have been investigated, and previous studies suggest that sub-Saharan African populations are at the highest risk for type 2 diabetes because of genetic factors despite the epidemiological observation that sub-Saharan Africa has relatively lower prevalence compared with most other regions in the world. ${ }^{53}$ When looking at genetic polymorphisms from patients around the world in the context of human migration, patients in sub-Saharan Africa were found to have the highest likelihood of type 2 diabetes, providing a plausible explanation for this increased risk as seen in Figure 4. This finding highlights the concern over the projected increase in the prevalence of diabetes as sub-Saharan Africa continues to rapidly urbanize and shift to a more urbanized lifestyle. Combining the explanation for increased genetic risk with an unparalleled lifestyle shift throughout sub-Saharan Africa could lead to increases in the number of patients with diabetes that surpass even the currently available projections of a $109 \%$ increase in prevalence over the next two decades. ${ }^{54}$

In comparative studies between white and black South African patients with impaired glucose tolerance, black patients showed a more rapid progression to type 2 diabetes. ${ }^{3,24}$

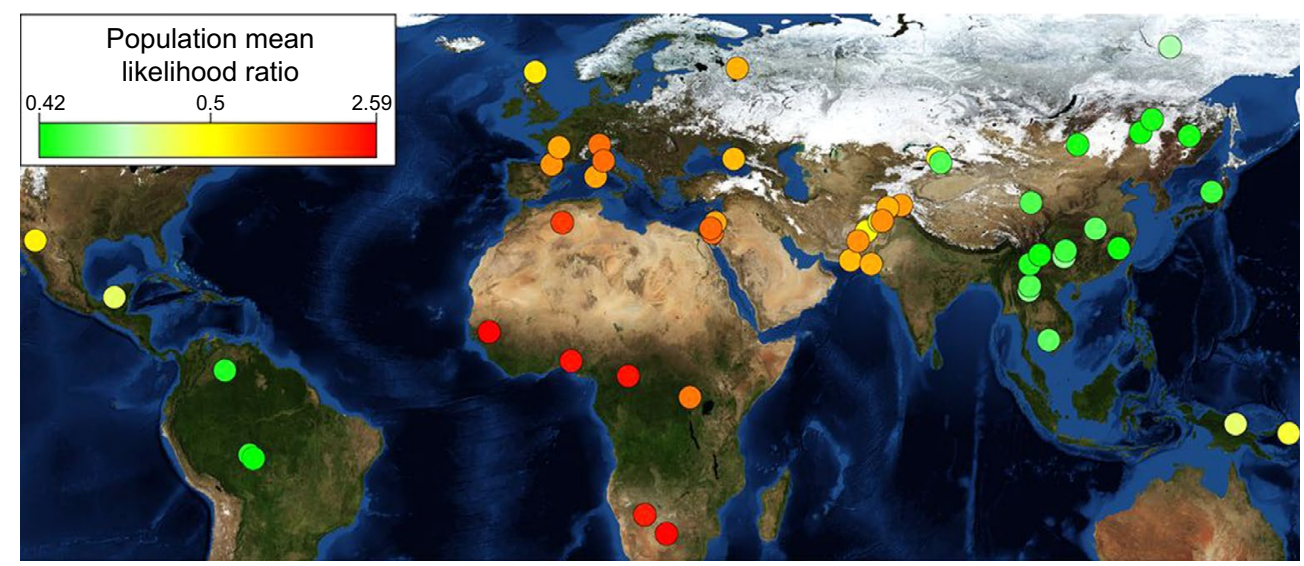

Figure 4 Likelihood of developing type 2 diabetes based on genetic polymorphisms.

Notes: Adapted from Corona E, Chen R, Sikora M, et al. Analysis of the genetic basis of disease in the context of worldwide human relationships and migration. PLoS Genet. 2013;9(5):el 003447 . Copyright (C) 2013 Corona et al. ${ }^{54}$ 
Reasons for the rapidly declining beta-cell function and more rapid progression of disease in sub-Saharan African patients are not conclusive at this time. Some hypotheses for this difference are differences in fat distribution as compared with other ethnicities, genetic variations among different subSaharan African populations, a genetic predisposition to less functional beta cells in African patients, environmental causes (such as toxins and infection), consequences of intrauterine growth retardation, and malnutrition. ${ }^{24}$

Type 2 diabetes in sub-Saharan Africa presents in multiple subtypes. Similar to what is typically seen in type 2 diabetes in Western settings, insulin resistance is associated with a BMI $\geq 25$, increased waist circumference, sedentary lifestyle, and high calorie diets, followed by a decrease in beta-cell function and eventual progression to type 2 diabetes in combination with metabolic syndromes associated with hypertension and dyslipidemias. ${ }^{3,17}$ This is seen primarily in urban settings and in patients of Asian descent and of mixed African and Middle Eastern heritage. Clinically, these patients are managed in the same way as type 2 diabetics in the Western settings and benefit from diet and exercise interventions as well as initial metformin therapy. ${ }^{3,17}$

Despite the positive link between obesity and diabetes in sub-Saharan African patients, a significant number of patients do not fit this traditional picture of type 2 diabetes. A unique subtype of type 2 diabetes, malnutrition-related diabetes, is manifested in patients who are normal or underweight (BMI $\leq 25)$ and develop the disease. ${ }^{24,29}$ This form of type 2 diabetes is seen primarily in rural sub-Saharan African patients. It is speculated that this form of the disease is caused by long-term malnutrition that eventually leads to pancreatic calcification. There is also suspicion that there may be a genetic link or infective process that accelerates the effects of malnutrition on the pancreas. Clinically, these patients present and are managed much differently than type 2 diabetes patients in the Western settings. These patients generally present with severe hyperglycemia and generally without ketones present. The initial episode is corrected with high-dose insulin, often exceeding 2 units/kg daily, although some patients are responsive to normal doses of insulin $(\leq 1$ unit $/ \mathrm{kg} /$ day). Once the initial episode is controlled, these patients have variable courses. Some patients may go into "remission" and not require insulin for weeks to years and remain ketosis-resistant, whereas some continue to require insulin, and others respond well to oral agents in the absence of insulin. This varying response to therapy and lack of radiology and laboratory data makes this form of diabetes difficult to distinguish from type 1 diabetes. ${ }^{24,29}$ Another subtype of type 2 diabetes found in the sub-Saharan African region is atypical African diabetes or ketosis-prone atypical diabetes. Typical presentation consists of polyuria, polydipsia, weight loss, and severe hyperglycemia with ketosis and is similar to the presentation of type 1 diabetes. These patients can be periodically managed with insulin, which can be discontinued and replaced by oral hypoglycemic agents until insulin is again necessary for control..$^{29,55}$

\section{Path to progress}

With the unique features of diabetes in sub-Saharan Africa, there needs to be considerable research on developing a better understanding of the dynamics of what seems to be a distinct disease process with different genotypic and phenotypic characteristics. These research efforts would unravel many of the mysteries surrounding diabetes in sub-Saharan Africa while simultaneously identifying contextualized management strategies that speak to the underlying mechanisms of the disease.

\section{Care protocols}

Despite many already described differences in diabetes found in sub-Saharan Africa, most sub-Saharan African country guidelines continue to rely heavily upon the guidelines used to govern the care of diabetes in HICs like the United States. This includes guidelines such as the American Diabetes Association (ADA) guidelines and the United Kingdom National Institute for Health and Clinical Excellence guidelines. The IDF also utilizes these guidelines to heavily inform their global guidelines on type 2 diabetes. With the vast majority of large randomized trials of diabetes enrolling participants from HICs, guideline committees, and task forces are all but required to rely on this high-quality data and extrapolate these findings to other populations in LMICs who do not have the luxury of relying on large randomized controlled trials incorporating their populations.

This is illustrated by the recommendations from all three major guidelines that suggest that metformin should be used as the first-line medication for type 2 diabetes. Based on many landmark studies including the United Kingdom Prospective Diabetes (UKPDS), which have enrolled populations from HICs with the prototypical version of type 2 diabetes, which includes increased waist circumference, increased BMI, and dyslipidemia. ${ }^{56,57}$

In the UKPDS study, for example, the average BMI was $27.5 \mathrm{~kg} / \mathrm{m}^{2}$ for all patients in the "normal" weight arm of the trial compared with a BMI of $31.4 \mathrm{~kg} / \mathrm{m}^{2}$ for the overweight 
arm of the study. By today's standards, the normal weight arm of the study would be considered overweight and the overweight arm would be considered obese. ${ }^{56,57}$ Although the UKPDS participants are representative of HIC populations and partially representative of the higher BMIs found in urban populations in sub-Saharan Africa, the applicability of the findings from this population to rural sub-Saharan Africa is limited considering the differences in patient characteristics. ${ }^{58}$ For example, in a study of 525 patients with diabetes in rural Kenya, $74 \%$ of the population had a BMI $<30$ despite being diagnosed with diabetes. ${ }^{59}$ With the marked differences in anthropometric characteristics, it is difficult to apply findings from studies like UKPDS to populations that do not have the same features. Furthermore, $<10 \%$ of any of the study arms from UKPDS comprised of patients of Afro-Caribbean descent further limiting the ability to extrapolate these landmark findings to populations in sub-Saharan Africa. ${ }^{57}$

Despite the lack of randomized controlled trial evidence to guide care in sub-Saharan Africa, clinicians and researchers from Partners in Health have developed contextualized guidelines that reflect the unique challenges commonly encountered while managing patients with diabetes in subSaharan Africa. ${ }^{60}$ Their overarching recommendations for the management of type 2 diabetes in LMICs can be seen in Figure 5. These guidelines provide much needed guidance to LMIC clinicians trying to manage the higher percentage of patients with normal or underweight diabetes. Instead of applying the typical approach of lifestyle modification followed by metformin, this guideline provides a much more contextualized approach that tailors treatment according to the BMI, limited selection of medications typically available, and blood glucose measurements that are available in facilities in LMICs. ${ }^{60}$

In contrast, the ADA guidelines illustrate various pharmacological approaches utilized in most HICs with an emphasis on metformin use for almost all patients. ${ }^{61}$ Although these guidelines are supported by large, randomized control trials, the applicability of these recommendations to sub-Saharan African populations is limited, as many of these medications are unavailable and cost prohibitive for most patients in the region. The ADA guidelines also fail to take into consideration the unique anthropometric characteristics of sub-Saharan Africa populations and more active lifestyle of rural sub-Saharan Africa populations. ${ }^{61}$

\section{Path to progress}

Many distinct features of diabetes in sub-Saharan Africa help to expose the immense need for care protocols that speak directly to various challenges that sub-Saharan Africa patients and clinicians face while trying to follow the guidelines developed for an entirely different population. As the number of patients with diabetes in sub-Saharan Africa increases continuously, the consumer demand for effective treatments will necessitate the identification of contextualized management strategies that help prevent the excess morbidity and mortality that patients are currently facing.

\section{Medication availability}

Increasing access to essential medicines is one of the targets of the Millennium Development Goals (MDGs). ${ }^{63}$ However, from a policy perspective, access to essential medicines has been neglected as a priority target for the MDGs, as evidenced by the fact that this target is missing from most of the MDGs reports. ${ }^{64}$ As a result, large disparities continue to exist in access to essential medicines between HICs and LMICs, as well as within different populations in the same country. Patients with chronic diseases in LMICs face several challenges in accessing medicines. These include poor availability and affordability of the medicines, inadequate public spending on health, high household out-of-pocket expenditure, and inadequate health insurance coverage. ${ }^{65}$ Chronic disease medications are even more burdened by limitations in access as significant differences in the availability of medicines for chronic diseases versus acute diseases in both public and private sector settings in LMICs have been reported (36\% vs $53.5 \%$ in the public sector and $54.7 \%$ vs $66.2 \%$ in the private sector). ${ }^{66}$

Cost is a significant barrier to access medicines for patients with diabetes in LMICS. In these populations, health care expenditure is mostly out-of-pocket, further propagating the vicious cycle of poverty as medicines consume large portions of household incomes. In Mali, for instance, care for a person with diabetes consumes nearly $70 \%$ of a family's income. ${ }^{67}$ In Nigeria, a monthly mean cost of $\$ 33.10$ for a person with diabetes was reported, which corresponds to $29 \%$ of the total monthly income of an individual on minimum wage.$^{68}$ Because of these stark realities, many patients opt to try to cope with diabetes without medications and suffer many preventable complications. In particular, lack of insulin in people with insulin-requiring diabetes can lead to DKA, and eventually death. Some sub-Saharan African countries have reported that up to $50 \%$ of deaths in patients with insulinrequiring diabetes were from DKA. ${ }^{69}$ Although programs like the IDF's Life for a Child have helped address the insulin needs of thousands of children with type 1 diabetes, large 


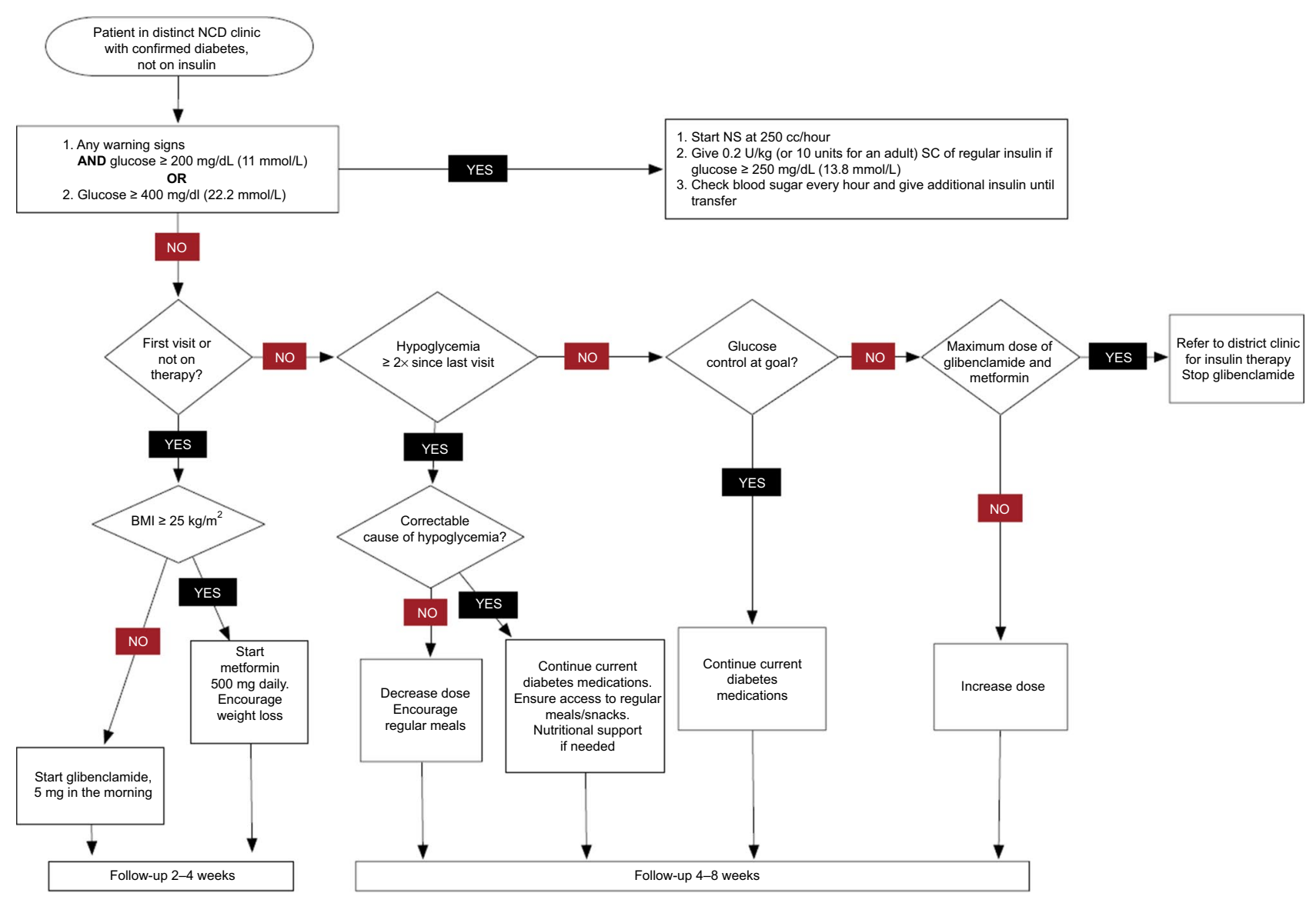

Figure 5 Diabetes management protocols.

Notes: Partners in health guidelines for type 2 diabetes management in low- and middle-income countries. Adapted from Kidder A, Kwan G, Cancedda C, Bukhman G. Diabetes. In: Bukhman G, Kidder A, editors. The PIH guide to chronic care integration for endemic non-communicable diseases. Rwanda ed. Boston, MA: Partners in Health; 20I I:153-187. Copyright (C 20II Partners In Health. All rights reserved under International and Pan-American Copyright Conventions.

Abbreviations: NCD, noncommunicable disease; NS, normal saline; SC, subcutaneous.

disparities exist in reliability and availability for insulin throughout sub-Saharan Africa. Past analyses have found that type 1 patients in Democratic Republic of Congo had access to insulin $<25 \%$ of the time. ${ }^{70}$ Similar studies from Tanzania found that different types of insulin were only available in public sector facilities $8 \%-17 \%$ of the time, and a separate analysis found that at least one version of insulin was available only $34 \%$ of the time. ${ }^{71,72}$ In one of the few formal published evaluations using the Rapid Assessment Protocol for Insulin Access (RAPIA) evaluations in Mozambique, supply was consistently available at only $20 \%$ of the hospital facilities and at none of the health centers. ${ }^{73}$ Even when this life-saving medication is available, the high prices of insulin and limited availability of reliable generics remain out of reach for most. In addition, reliable and affordable access to insulin syringes, as well as blood glucose testing devices and test-strips that are essential for optimal glycemic control pose a challenge to many people with diabetes. ${ }^{67,73}$

\section{Rational selection of medicines}

Appropriate selection of medicines can significantly improve coverage within limited budgets. The WHO publishes a Model List of Essential Medicines that provides a framework from which other countries can develop their National Essential Medicines List (NEML). NEMLs are important in ensuring countries appropriately prioritize their expenditure on evidence-based, cost-effective medicines. ${ }^{74}$ However, only $38 \%$ of 15 sub-Saharan countries had updated their NEML in the past 5 years. ${ }^{64}$ The WHO Model List of Essential Medicines includes both shortacting and long-acting insulin formulations, as well as oral hypoglycemic agents. ${ }^{52}$ An evaluation of NEMLs in 2014 reported that although these medicines were present in the NEMLs of almost all of the 32 LMICs included in the survey, they were still not adequately available and affordable in these countries, suggesting poor implementation of the NEMLs. ${ }^{74}$ 


\section{Use of generic medicines}

Generic medicines increase competition and have been shown to significantly reduce the cost of essential medicines. For example, the introduction of generic oral hypoglycemic agents has reduced their cost to $<\$ 1$ per month. Although oral hypoglycemic agents have enjoyed significant cost reductions over the last few years as a result of the introduction of their generic counterparts, this has not been the case with insulin which has consistently remained unaffordable to most people with diabetes in sub-Saharan Africa. Among the barriers limiting the use of generic insulin are legal barriers and patent restrictions such as the Trade Related Aspects of Intellectual Property Rights agreement. Most of the oral hypoglycemic medicines on the WHO Model List are off-patent and are therefore not adversely affected by the international property rights laws. Although human insulin is also off-patent, it is still unavailable in many LMICs. The pharmaceutical industry has been criticized for incremental improvements that increase the patent life of insulin, leading to what is now being termed as "evergreening." As a result of these tactics, insulin has remained largely unaffordable in many countries over the years. However, data on the quality of the insulin manufactured in these countries has not been reliably ascertained. Generic medicines have to undergo bioequivalence testing to ensure that they conform to safety and efficacy standards similar to the innovator brands. The majority of LMICs do not have the capacity to carry out their own independent quality assurance tests on generic medicines and have to rely on HICs or the WHO..$^{75,76}$ The WHO has a prequalification program that assures the quality and safety of generics such as medicines for HIV and malaria. However, suppliers of insulin are yet to be prequalified as the WHO cites lack of funds, instead focusing on the more pressing infectious diseases. ${ }^{76}$

\section{Path to progress}

Providing access to medicines is one of the cornerstones of ensuring optimal care for people with diabetes in sub-Saharan Africa. However, this will require coordinated efforts from all stakeholders along the continuum of care. Governments have a duty and responsibility to ensure that medicines are available and affordable to all their citizens. However, poor financing and fragmented supply chain systems have resulted in chronic deficiencies of essential medicines in sub-Saharan Africa, especially within the public sector. Addressing challenges with selection and pricing of drugs during procurement will ensure that governments get the best value for money and significantly increase affordability of medicines to the end users. Fortunately, the Sustainable
Development Goals have recently included a specific target of ensuring access to medicines and pursuing research on NCDs in LMICs which will hopefully increase the availability of effective diabetes medications. ${ }^{77}$

Furthermore, to maximize the benefits of these medications, the entire health care infrastructure must be strengthened and redesigned to ensure that these medicines reach patients and are appropriately monitored to maximize benefits and minimize risks.

\section{Systems of care}

Much like other chronic diseases, diabetes is a disease whose management requires significant coordination between many different aspects of the health care delivery system. ${ }^{1}$ This requirement for coordination has been consistently found in all settings, regardless of income, and is especially pronounced for diabetes considering the multiple organ systems that diabetes affects. However, significant challenges are faced in settings where limited human resources for health combine to disrupt efforts to create cohesive and adequately staffed care delivery systems. ${ }^{78}$

The limited organization complicates care as patients face considerable difficulty transitioning between initial screening, outpatient care, inpatient care, and self-management. As seen in Table 1, the key overarching challenges within each of these nodes of the health care system are illustrated with the poor resultant outcomes of this fragmented approach.

\section{Screening/prevention}

In terms of screening, sub-Saharan Africa is plagued with the lowest rates of diagnosis in the world. ${ }^{2}$ With the limited emphasis on preventative medicine compared with the typical focus on acute health care needs found in most LMICs, patients are rarely presented with opportunities for the early diagnosis of diabetes before symptoms and life-threatening complications set in. Even when symptoms set in, the relatively low level of awareness among providers and the community combined with the aforementioned limitations in testing supplies prevents patients from getting the early intervention they desperately need. Pilot efforts to combat this have focused on screening high-risk populations that fit the determinants of disease identified in HICs. ${ }^{79}$ Although this strategy has been effective for urban populations, its applicability to rural populations is limited as the dynamics of disease are dramatically different and the typical emphasis on lifestyle modifications for populations that already engage in highly active lifestyles with limited dietary options have limited resonance with the population in question. ${ }^{43}$ Although most diabetes prevention and management efforts 
Table I Overarching challenges and outcomes found in different levels of the health care system in sub-Saharan Africa (SSA)

\begin{tabular}{|c|c|c|c|c|}
\hline Screening/prevention & Outpatient care & Inpatient care & Self-management & Outcomes \\
\hline $\begin{array}{l}\text { Routine screening } \\
\text { largely unavailable } \\
\text { - When screening is } \\
\text { conducted, less than } \\
30 \% \text { link to care in the } \\
\text { public sector }\end{array}$ & $\begin{array}{l}\text { - Limited access to } \\
\text { HbAlc and other vital } \\
\text { laboratory tests }\end{array}$ & $\begin{array}{l}\text { - Inadequate } \\
\text { infrastructure to manage } \\
\text { hyperglycemic crises } \\
\text { - Unacceptably high } \\
\text { mortality rates from } \\
\text { hyperglycemic crises }\end{array}$ & $\begin{array}{l}\text { - Limited affordability and } \\
\text { infrastructure to support home } \\
\text { glucose monitoring } \\
\text { - Many public sector facilities } \\
\text { require patients to come to } \\
\text { facilities twice a day to receive } \\
\text { direct insulin administration }\end{array}$ & $\begin{array}{l}\text { - Highest mortality rate } \\
\text { from diabetes in the } \\
\text { world } \\
\text { - Largest undiagnosed } \\
\text { population of diabetes } \\
\text { in the world with } \\
\text { over } 62 \% \text { remaining } \\
\text { undiagnosed }\end{array}$ \\
\hline $\begin{array}{l}\text { - Limited emphasis on } \\
\text { prevention and unclear } \\
\text { prevention strategy in } \\
\text { rural settings }\end{array}$ & $\begin{array}{l}\text { - High diabetes-related } \\
\text { complication rates }\end{array}$ & $\begin{array}{l}\text { - Limited access to } \\
\text { specialized management } \\
\text { of complications }\end{array}$ & $\begin{array}{l}\text { - Limited availability of peer } \\
\text { support, educational programs } \\
\text { or peer-based care }\end{array}$ & $\begin{array}{l}\text { - SSA has the greatest } \\
\text { anticipated increase in } \\
\text { diabetes prevalence }\end{array}$ \\
\hline
\end{tabular}

typically focus on caloric restriction, studies from rural settings in sub-Saharan Africa have found that $30 \%$ of diabetes patients in a rural, public sector clinic report some level of food insecurity. ${ }^{80}$ It is because of atypical characteristics like this and the higher prevalence of understudied variants that rural populations require distinct education, screening, and management strategies.

\section{Outpatient care}

Although there are clear deficiencies within the current screening and prevention strategies utilized in sub-Saharan Africa, even more pressing needs exist within the availability of reliable and impactful outpatient care that screenpositive patients would depend on. With many limitations in policy focus and attention given to NCDs like diabetes, the poor quality of outpatient care for diabetes serves as a microcosm for all other NCDs in sub-Saharan Africa. The current state of diabetes care is an almost inevitable consequence of the many gaps in care described throughout this review. In addressing the key gaps in outpatient care, several fundamental aspects must be considered. Prior to the rapid rise in diabetes seen over the last two decades, diabetes was a relatively rare condition in rural sub-Saharan Africa and a somewhat uncommon condition even in urban settings. ${ }^{3}$ At the same time, communicable diseases were gaining considerable attention because of their disproportionate toll on sub-Saharan African societies. Because of these dynamics, the emphasis and focus on training health care providers about diabetes was often sacrificed in the interest of promoting education for heavily funded diseases including TB, HIV, and malaria. This has created a vacuum where providers and ministries of health have become experts on management and creation of infrastructure to handle the acute complications of communicable diseases but have de-emphasized the creation of infrastructure designed to handle the chronic disease management needs of patients. Although there are many ongoing efforts focused on expanding the benefits of HIV health care infrastructure to other chronic diseases, these efforts are still largely limited to small pilots that have not been scaled. ${ }^{81-84}$

The disparity in outpatient care is further complicated by the dichotomy seen between population dense urban areas that attract the majority of diabetes-trained providers compared with rural areas that have only limited health care worker resources to handle a much larger population scattered over a vast terrain. ${ }^{63}$ This drastic disparity between rural and urban settings is illustrated in all facets of outpatient diabetes management with patients from urban settings typically having much greater access to specialized care for diabetes-related complications, diabetes-specific laboratory tests, and newer medications. Urban settings also tend to have a higher predominance of patients with the ability to pay higher private sector prices. These factors have created a situation where infrastructure for tests like the glycosylated hemoglobin (HbA1c) are readily available in urban private sector facilities while being absent in rural areas that largely rely on public sector health care delivery. For example, in Kenya, the disparity in pricing and uptake can be seen where private sector providers charge $\sim$ US $\$ 25$ per HbA1c test compared with US\$10 in the public sector. Despite the much lower charges in the public sector, $<20 \%$ of patients perform this vital test. ${ }^{85,86}$

Instead, most patients in the public sector rely on a single random blood glucose (if available) on the day of their visit to determine the status of their diabetes while visiting health care providers. All these factors have left patients with diabetes with a very bleak picture as they try to prevent the inevitable, insidious complications of diabetes. Even when patients do screen positive for diabetes in the community, there is considerable reluctance with accessing care at public sector facilities with findings from rural sub-Saharan African settings, illustrating that $<25 \%$ return for confirmation despite phone-based follow-up and reminders. ${ }^{7}$ In further qualitative analyses of barriers to linkage to care for NCD 
patients, patients frequently mention the financial challenges in addressing NCDs, poor quality of public sector facilities, feeling like they are a burden to the family, and the distant travel required to reach the facilities. ${ }^{87}$

Similar to HIV patients in sub-Saharan Africa, prior to the provision of highly active antiretroviral therapy, diabetes patients are left with few outpatient management options as the current costs of care are exorbitantly high in relation to their earnings with high-quality access being reserved for the few patients who can afford it. This has created a dynamic where diabetes patients frequently rely on inpatient care to provide short-term fixes for their acute complications or rely on facilities to serve as their final resting place as their health care needs surpass the currently available infrastructure. The unfortunate reality that inpatient providers face in managing diabetes is eerily reminiscent of the situation faced when trying to cope with the preventable mortalities faced during the height of the HIV epidemic in sub-Saharan Africa.

\section{Inpatient care}

Although inpatient care is typically intended to address the short-term, acute complications of diabetes, it is commonly used to fill in the gaps in outpatient care. With the frequent medication stock-outs, difficulties with accessing insulin, and suboptimally managed and diagnosed infectious diseases, patients are often prone to frequent bouts of hyperglycemia requiring inpatient admission and insulin administration..$^{88,89}$

Unfortunately, this reliance on ill-equipped inpatient facilities leads to unacceptably high levels of mortality from the different manifestations of hyperglycemia. For example, past studies in sub-Saharan Africa have found high mortality rates of $25 \%-33 \%$ for patients presenting to the hospital with DKA. This is in contrast to the much lower mortality rates of $2 \%-5 \%$ found for DKA in HIC inpatient settings. The risk of death from hyperosmolar non-ketotic coma is even more concerning as past studies in South Africa found a $44 \%$ mortality rate within an inpatient setting compared with $\sim 15 \%$ from data obtained from HICs over 20 years ago. ${ }^{43,90-92}$

Although these mortality rates for inpatient care are quite concerning, this only represents the small fraction of the population of patients who are even able to make it to an inpatient facility for the management of their acute diabetes complications. The lack of access to high-quality diabetes care combined with the suboptimal performance of hospitals contributes to the alarmingly high early mortality subSaharan African patients face with $76 \%$ of diabetes-related death occurring before the age of $60 .^{2}$
In addition to reliance on inpatient care for management of acute complications, the inevitable consequences of diabetes on other organ systems stretches limited resources even further. With the high rates of diabetes-related kidney injury, a large proportion of patients with diabetes who are able to survive beyond the age of 60 years eventually require dialysis. Despite the relatively low prevalence of diabetes found in sub-Saharan Africa, diabetes was one of the main drivers of end-stage renal disease even in data obtained over 15 years ago. ${ }^{92}$ More than one third of patients receiving care within dialysis units had diabetes. ${ }^{43,94}$ The importance of addressing kidney-related complications cannot be understated, as it is estimated that $50 \%$ of the diabetes-related mortality is attributed to renal disease even in patients with type 1 diabetes. ${ }^{43}$

With the dramatically higher rates of kidney dysfunction, the availability of dialysis units is quickly outpaced by the numbers of patients with diabetes-related end-stage renal disease requiring long-term dialysis for survival. In addition to the reliance on inpatient care for complications associated with hyperglycemia, patients in sub-Saharan Africa often require hospitalizations for hypoglycemia. With the limited options for medications and unique pathophysiology of diabetes in sub-Saharan Africa, patients are often prescribed sulfonylureas and/or insulin. This has contributed to frequent bouts of hypoglycemia that have become an all too common cause of preventable inpatient admission and excess morbidity and mortality. The limited provision of counseling with the prescription of these medications, combined with the high rates of food insecurity leads to a potentially lethal situation. In order to combat this, strategies to combat the many preventable causes of inpatient admission must include a shift from continued reliance on limited health care worker resources toward care systems that equip patients with highly effective self-management strategies to independently address many of these preventable situations.

\section{Self-management}

With many aforementioned deficiencies in care provision, there has only been limited effort in building the structures necessary to promote safe and effective self-management strategies. Although self-monitored blood glucose (SMBG) has become a prerequisite component of care for patients with diabetes in HICs, especially those requiring insulin, this modality of care is largely inaccessible in sub-Saharan Africa. The relatively high cost, time intensive nature, high demands on limited health care worker resource, and coordination of care required for SMBG have resulted in lower prioritization of this proven care strategy. Despite several pilot investigations 
in sub-Saharan Africa demonstrating the feasibility and $>30 \%$ reductions in the $\mathrm{HbA1c}$ after just 3 months of SMBG with phone-based support, provision of this service is still slow to reach even private sector settings. ${ }^{29,95,96}$ Although wide-scale provision of this service would undoubtedly improve care, a more cost-effective strategy that incorporates many of the task shifting care strategies utilized with other chronic diseases like HIV could lead to dramatic, sustainable impact for diabetes care. For example, the incorporation of community health workers into the HIV delivery system has reduced the overarching cost of care delivery while simultaneously improving patient outcomes. This transition to community health workers could have similar benefits for diabetes. ${ }^{97,98}$

Pilot strategies including the provision of contextualized diabetes awareness materials utilizing conversation maps to provide group-based diabetes education have demonstrated effectiveness, however, are still relegated to relatively smallscale impact as they have not yet been broadly scaled up. ${ }^{99,100}$

Other strategies have succeeded in creating sustainable and impactful care delivery by linking group-based microfinance to portable group-based care delivery for NCDs. ${ }^{101}$ Although most of these pilots have been limited to very small-scale implementations, it is clear that a successful long-term solution requires consideration of the multifaceted challenges that patients in sub-Saharan Africa face in trying to access and pay for higher quality care.

\section{Path to progress}

With many deficits in various levels of the health care system, there needs to be a significant investment in both the public and private sectors to raise the level of care patients can rely on while seeking desperately needed services. However, to ensure long-term sustainability of these services, large-scale integration with other well developed health care infrastructure (ie, HIV), novel payment strategies, and care delivery methods must be considered to promote the implementation of more patient-centric services that meet the demands and unique needs of patients with diabetes in sub-Saharan Africa.

\section{Discussion/conclusion}

With the marked uniqueness of diabetes in sub-Saharan Africa in all aspects of the disease, it is clear that there is much needed effort to pursue sub-Saharan Africa-specific diabetes research rather than the current approach of relying on lessons learned from HICs to a dissimilar disease process, policy landscape, and markedly different health care system. Although there are many unanswered questions surrounding diabetes in sub-Saharan Africa, it is clear that there are many solvable immediate needs that need to be addressed to prevent the unacceptably high levels of excess morbidity and mortality that the patients are currently experiencing.

\section{Acknowledgment}

Dr Chelsea R Pekny is now an assistant professor at The Ohio State University College of Pharmacy.

\section{Disclosure}

The authors report no conflicts of interest in this work.

\section{References}

1. Triad Study Group. Health systems, patients factors, and quality of care for diabetes: a synthesis of findings from the TRIAD study. Diabetes Care. 2010;33(4):940-947.

2. International Diabetes Federation. IDF Diabetes Atlas, 7th ed. Available from: http://www.idf.org/diabetesatlas. Accessed April 3, 2015.

3. Mbanya JC, Motala AA, Sobngwi E, Assah FK, Enoru ST. Diabetes in sub-Saharan Africa. Lancet. 2010;375(9733):2254-2266.

4. Jamison DT, Feachem RG, Makgoba MW, et al. Disease and mortality in Sub-Saharan Africa. 2nd ed. Washington, DC: The World Bank; 2006.

5. Hu FB, Satija A, Manson JE. Curbing the diabetes pandemic: the need for global policy solutions. JAMA. 2015;313(23):2319-2320.

6. Pastakia SD, Ogallo W. 2014 Prescott lecture: designed to fail, reengineered to succeed. J Am Pharm Assoc. 2014;54(4):350-354, 356.

7. Pastakia SD, Ali SM, Kamano JH, et al. Screening for diabetes and hypertension in a rural low income setting in western Kenya utilizing home-based and community-based strategies. Global Health. 2013;9:21.

8. Gates B. The next epidemic--lessons from Ebola. $N$ Engl J Med. 2015;372(15):1381-1384.

9. Alleyne G, Binagwaho A, Haines A, et al. Embedding non-communicable diseases in the post-2015 development agenda. Lancet. 2013;381(9866):566-574.

10. Independent Task Force on Noncommunicable Diseases: The Emerging Global Health Crisis: Noncommunicable Diseases in Low- and Middle-Income Countries, Task Force Report No. 72. New York: Council on Foreign Relations Press; 2014.

11. Beaglehole R, Bonita R, Alleyne G, et al. UN high-level meeting on non-communicable diseases: addressing four questions. Lancet. 2011;378(9789):449-455.

12. http://data.worldbank.org [homepage on the Internet]. The World Bank Group, Washington, DC; 2015 [updated June 24, 2015; cited June 25, 2015]. Available from: http://data.worldbank.org/indicator/SH.XPD. TOTL.ZS/countries/ZF-XN?display=graph. Accessed June 25, 2015.

13. http://data.worldbank.org [homepage on the Internet]. The World Bank Group, Washington, DC; 2015 [updated June 24, 2015; cited June 25, 2015]. Available from: http://data.worldbank.org/indicator/ SH.XPD.PUBL/countries/ZF-XN?display=graph. Accessed June 25, 2015.

14. de-Graft Aikins A, Unwin N, Agyemang C, Allotey P, Campbell C, Arhinful D. Tackling Africa's chronic disease burden: from the local to the global. Global Health. 2010;6:5.

15. Bauman A, Schoeppe S, Lewicka M, Armstrong T, Candeias V, Richards J. Review of best practice in interventions to promote physical activity in developing countries background document. World Health Organization 2005: WHO Workshop on Physical Activity and Public Health; 2005 October 24-27; Beijing, China.

16. Qi Q, Chu AY, Kang JH, et al. Sugar-sweetened beverages and genetic risk of obesity. N Engl J Med. 2012;367(15):1387-1396.

17. Hall V, Thomsen RW, Henriksen O, Lohse N. Diabetes in Sub Saharan Africa 1999-2011: epidemiology and public health implications. A systematic review. BMC Public Health. 2011;11:564. 
18. Sobngwi E, Mauvais-Jarvis F, Vexiau P, Mbanya JC, Gautier JF. Diabetes in Africans. Part 1: epidemiology and clinical specificities. Diabetes Metab J. 2001;27(6):628-634.

19. Kandala NB, Stranges S. Geographic variation of overweight and obesity among women in Nigeria: a case for nutritional transition in sub-Saharan Africa. PLoS One. 2014;9(6):e101103.

20. Mennen LI, Mbanya JC, Cade J, et al. The habitual diet in rural and urban Cameroon. Eur J Clin Nutr. 2000;54(2):150-154.

21. Kiawi E, Edwards R, Shu J, Unwin N, Kamadjeu R, Mbanya JC. Knowledge, attitudes, and behavior relating to diabetes and its main risk factors among urban residents in Cameroon: a qualitative survey. Ethn Dis. 2006;16(2):503-509.

22. Renzaho AM. Fat, rich and beautiful: changing socio-cultural paradigms associated with obesity risk, nutritional status and refugee children from sub-Saharan Africa. Health Place. 2004;10(1):105-113.

23. Urbanization in Africa. December 2012. Available from: http://www. afdb.org/en/blogs/afdb-championing-inclusive-growth-across-africa/ post/urbanization-in-africa-10143/. Accessed April 1, 2015.

24. Osei K, Schuster DP, Amoah AG, Owusu SK. Diabetes in Africa. Pathogenesis of type 1 and type 2 diabetes mellitus in sub-Saharan Africa: implications for transitional populations. J Cardiovasc Risk. 2003;10(2):85-96.

25. Beran, D. The Diabetes Foundation Report on Implementing National Diabetes Programmes in Sub-Saharan Africa. London: International Insulin Foundation; 2006.

26. Young F, Critchley JA, Johnstone LK, Unwin NC. A review of comorbidity between infectious and chronic disease in Sub Saharan Africa: TB and diabetes mellitus HIV and metabolic syndrome, and the impact of globalization. Global Health. 2009;5:9.

27. Dooley KE, Chaisson RE. Tuberculosis and diabetes mellitus: convergence of two epidemics. Lancet Infect Dis. 2009;9(12):737-746.

28. van Crevel R, Dockrell HM; for Tandem Consortium. TANDEM: understanding diabetes and tuberculosis. Lancet Diabetes Endocrinol. 2014;2(4):270-272.

29. Gill GV, Mbanya JC, Ramaiya KL, Tesfaye S. A sub-Saharan African perspective of diabetes. Diabetologia. 2009;52(1):8-16.

30. Kalra S, Kalra B, Agrawal N, Unnikrishnan A. Understanding diabetes in patients with HIV/AIDS. Diabetol Metab Syndr. 2011:3(1):2.

31. Mbanya JC, Sobngwi E. Diabetes in Africa. Diabetes microvascular and macrovascular disease in Africa. J Cardiovasc Risk. 2003;10(2):97-102.

32. Mengesha AY. Spectrum of eye disorders among diabetes mellitus patients in Gaborone, Botswana. Trop Doct. 2006;36(2):109-111.

33. Sobngwi E, Mbanya JC, Moukouri EN, Ngu KB. Microalbuminuria and retinopathy in a diabetic population of Cameroon. Diabetes Res Clin Pract. 1999;44(3):191-196.

34. Seyoum B, Mengistu Z, Berhanu P, et al. Retinopathy in patients of Tikur Anbessa Hospital diabetic clinic. Ethiop Med J. 2001;39(2):123-131.

35. Rotimi C, Daniel H, Zhou J, et al. Prevalence and determinants of diabetic retinopathy and cataracts in West African type 2 diabetes patients. Ethn Dis. 2003;13(2 Suppl 2):S110-S117.

36. Omolase CO, Adekanle O, Owoeye JF, Omolase BO. Diabetic retinopathy in a Nigerian community. Singapore Med J. 2010;51(1):56-59.

37. Mwale C, Karimurio J, Njuguna M. Refractive errors in type 2 diabetic patients. East Afr Med J. 2007;84(6):259-263.

38. Read O, Cook C. Retinopathy in diabetic patients evaluated at a primary care clinic in Cape Town. S Afr Med J. 2007;97(10):941-942, 944.

39. Mash B, Powell D, du Plessis F, van Vuuren U, Michalowska M, Levitt N. Screening for diabetic retinopathy in primary care with a mobile fundal camera--evaluation of a South African pilot project. SAfr Med J. 2007;97(12):1284-1288.

40. Odusan O, Familoni OB, Raimi TH. Correlates of cardiac autonomic neuropathy in Nigerian patients with type 2 diabetes mellitus. Afr $J$ Med Med Sci. 2008;37(4):315-320.

41. Ahmed AM, Hussein A, Ahmed NH. Diabetic autonomic neuropathy. Saudi Med J. 2000;21(11):1034-1037.

42. Unuigbe EI, Omeife H, Edema T, Ukoli FA. Microalbuminuria and associated factors in newly diagnosed diabetics. Niger Postgrad Med J. 2001;8(4):187-192.
43. Mbanya JC, Ramiaya K. Diabetes mellitus. In: Jamison DT, Feachem RG, Makgoba MW, et al., editors. Disease and Mortality in SubSaharan Africa. 2nd ed. Washington, DC: The International Bank for Reconstruction and Development / The World Bank; 2006.

44. Wanjohi FW, Otieno FC, Ogola EN, Amayo EO. Nephropathy in patients with recently diagnosed type 2 diabetes mellitus in black Africans. East Afr Med J. 2002;79(8):399-404.

45. Mwendwa FM, Otieno CF, Kayima JK, Amayo EO, Otieno PO. Risk factor profile and the occurrence of microvascular complications in short-term type 2 diabetes mellitus at Kenyatta National Hospital, Nairobi. East Afr Med J. 2005;82(12 Suppl):S163-S172.

46. Motala AA, Pirie FJ, Gouws E, Amod A, Omar MA. Microvascular complications in South African patients with long-duration diabetes mellitus. S Afr Med J. 2001;91(11):987-992.

47. Majaliwa ES, Munubhi E, Ramaiya K, et al. Survey on acute and chronic complications in children and adolescents with type 1 diabetes at Muhimbili National Hospital in Dar es Salaam, Tanzania. Diabetes Care. 2007;30(9):2187-2192.

48. Kalk WJ, Joffe BI. Differences in coronary heart disease prevalence and risk factors in African and White patients with type 2 diabetes. Diabetes Res Clin Pract. 2007;77(1):107-112.

49. Shirey K, Manyara SM, Atwoli L, et al. Symptoms of depression among patients attending a diabetes care clinic in rural western Kenya. J Clin Transl Endocrinol. 2015;2(2):51-54.

50. Saxena S, Thornicroft G, Knapp M, Whiteford H. Resources for mental health: scarcity, inequity, and inefficiency. Lancet. 2007;370(9590):878-889.

51. Lund C, De Silva M, Plagerson S, et al. Poverty and mental disorders: breaking the cycle in low-income and middle-income countries. Lancet. 2011;378(9801):1502-1514.

52. Beran D, Yudkin JS. Diabetes care in sub-Saharan Africa. Lancet. 2006;368(9548):1689-1695.

53. Chen R, Corona E, Sikora M, et al. Type 2 diabetes risk alleles demonstrate extreme directional differentiation among human populations, compared to other diseases. PLoS Genet. 2012;8(4):e1002621.

54. Corona E, Chen R, Sikora M, et al. Analysis of the genetic basis of disease in the context of worldwide human relationships and migration. PLoS Genet. 2013;9(5):e1003447.

55. Sobngwi E, Mauvais-Jarvis F, Vexiau P, Mbanya JC, Gautier JF. Diabetes in Africans. Part 2: Ketosis-prone atypical diabetes mellitus. Diabetes Metab. 2002;28(1):5-12.

56. Intensive blood-glucose control with sulphonylureas or insulin compared with conventional treatment and risk of complications in patients with type 2 diabetes (UKPDS 33). UK Prospective Diabetes Study (UKPDS) Group. Lancet. 1998;352(9131):837-853.

57. Effect of intensive blood-glucose control with metformin on complications in overweight patients with type 2 diabetes (UKPDS 34). UK Prospective Diabetes Study (UKPDS) Group. Lancet. 1998;352(9131):854-865.

58. Ekoé JM, Zimmet P, Williams R. An international perspective. In: Ekoé JM, Zimmet P, Williams R, editors. The Epidemiology of Diabetes Mellitus: An International Perspective. 1st ed. Chinchester, UK: John Wiley \& Sons Ltd; 2001. Available from: https://books.google.co.ke/ books?isbn=0470779764.

59. Cheng S, Patel J, Pastakia S, et al. The Implementation of Comprehensive Diabetes Care in a Rural Resource-Constrained Setting. 45th American Society of Health System Pharmacists Annual Meeting. Anaheim, CA. December 6, 2010.

60. Kidder A, Kwan G, Cancedda C, Bukhman G. Diabetes. In: Bukhman G, Kidder A, editors. The PIH guide to chronic care integration for endemic non-communicable diseases. Rwanda ed. Boston, MA: Partners in Health; 2011:153-187.

61. Inzucchi SE, Bergenstal RM, Buse JB, et al.; American Diabetes Association (ADA); European Association for the Study of Diabetes (EASD). Management of hyperglycemia in type 2 diabetes:a patientcentered approach. Position statement of the American Diabetes Association (ADA) and the European Association for the Study of Diabetes (EASD). Diabetes Care. 2012;35:1364-1379. 
62. American Diabetes Association. Standards of medical care in diabetes-2014. Diabetes Care. 2014;37(Suppl 1):S14-S80.

63. Millennium Development Goals Gap Task Force. Millennium Development Goal 8: The Global Partnership for Development: Making Rhetoric a Reality. New York: United Nations Millennium Development Goals Gap Task Force; 2012.

64. Hogerzeil HV, Liberman J, Wirtz VJ, et al. Promotion of access to essential medicines for non-communicable diseases: practical implications of the UN political declaration. Lancet. 2013;381(9867):680-689.

65. Kanavos PG, Vandoros S. Determinants of branded prescription medicine prices in OECD countries. Health Econ Policy Law. 2011;6(3):337-367.

66. Cameron A, Roubos I, Ewen M, Mantel-Teeuwisse AK, Leufkens HG, Laing RO. Differences in the availability of medicines for chronic and acute conditions in the public and private sectors of developing countries. Bull World Health Organ. 2011;89(6):412-421.

67. International Insulin Foundation. The Diabetes Foundation report on insulin-requiring diabetes in sub-Saharan Africa (2002-2004). Accessed July 8, 2015.

68. Ogbera AO, Kuku SF. Insulin use, prescription patterns, regimens and costs. A narrative from a developing country. Diabetol Metab Syndr. 2012;4(1):50.

69. Azevedo M, Alla S. Diabetes in sub-Saharan Africa: Kenya, Mali, Mozambique, Nigeria, South Africa and Zambia. Int J Diabetes Dev Ctries. 2008;28(4):101-108.

70. Peck R, Mghamba J, Vanobberghen F, et al. Preparedness of Tanzanian health facilities for outpatient primary care of hypertension and diabetes: a cross-sectional survey. Lancet Global Health. 2014;2(5):e285-e292.

71. Ministry of Health and Social Welfare, Tanzania. Tanzania Service Availability and Readiness Assessment (2012). Final report July 2013. Available from: http://www.ihi.or.tz/ announ/availabilityand readinessassessmentresultsannounced. Accessed June 1, 2016.

72. O’Neill K, Takane M, Sheffel A, Abou-Zahr C, Boerma T. Monitoring service delivery for universal health coverage: the service availability and readiness assessment. Bull World Health Organ. 2013;91:923-931.

73. Beran D, Yudkin JS, de Courten M. Access to care for patients with insulin-requiring diabetes in developing countries: case studies of Mozambique and Zambia. Diabetes Care. 2005;28(9):2136-2140.

74. Bazargani YT, de Boer A, Leufkens HG, Mantel-Teeuwisse AK. Selection of essential medicines for diabetes in low and middle income countries: a survey of 32 national essential medicines lists. PLoS One. 2014;9(9):e106072.

75. Greene JA, Riggs KR. Why is there no generic insulin? Historical origins of a modern problem. NEngl J Med.2015;372(12):1171-1175.

76. Home P. Biosimilar insulins. Diabetes Voice. September 13, 2011: $40-43$.

77. UN. Transforming our world: the 2030 Agenda for Sustainable Development. New York: United Nations; 2015. Available from: https:// sustainabledevelopment.un.org/post2015/transformingourworld. Accessed September 14, 2015.

78. Adwok J, Kearns EH, Nyary B. Fragmentation of health care delivery services in Africa: responsible roles of financial donors and project implementers. Developing Country Studies. 2013;3(5) (online).

79. Diop SN. Screening and prevention of diabetes: implications for Sub Saharan Africa. Diabetes Res Clin Pract. 2014;103:S6-S7.

80. Cheng S, Kamano J, Kirui NK, et al. Prevalence of food insecurity in patients with diabetes in western Kenya. Diabet Med. 2013;30(6):e215-e222.

81. Nigatu T. Integration of HIV and noncommunicable diseases in health care delivery in low- and middle-income countries. Prev Chronic Dis. 2012;9:E93.

82. Mills A. Vertical vs horizontal health programmes in Africa: idealism, pragmatism, resources and efficiency. Soc Sci Med. 1983;17(24):1971-1981.
83. Janssens B, Van Damme W, Raleigh B, et al. Offering integrated care for HIV/AIDS, diabetes and hypertension within chronic disease clinics in Cambodia. Bull World Health Organ. 2007;85(11):880-885.

84. UNAIDS. Chronic care of HIV and non-communicable diseases: how to leverage the HIV experience. 2011. Available from: http://www. unaids.org/en/media/unaids/contentassets/documents/unaidspublication/2011/20110526_JC2145_Chronic_care_of_HIV.pdf. Accessed June 15, 2015.

85. Matheka DM, Kilonzo JM, Munguti CM, Mwangi PW. Pattern, knowledge and practices of $\mathrm{HbA} 1 \mathrm{C}$ testing among diabetic patients in a Kenyan tertiary referral hospital. Global Health. 2013;9:55.

86. Karongo C. WHO approved diabetes kit costly for Kenya Nairobi, Kenya: Capital Broadcasting Network; 2011. Available from: http:// www.capitalfm.co.ke/news/2011/01/who-approved-diabetes-kitcostly-for-kenya/. Accessed June 2, 2015.

87. Vedanthan R, Kamano JH, Naanyu V, et al. Optimizing linkage and retention to hypertension care in rural Kenya (LARK hypertension study): study protocol for a randomized controlled trial. Trials. 2014;15:143.

88. Chale SS, Swai AB, Mujinja PG, McLarty DG. Must diabetes be a fatal disease in Africa? Study of costs of treatment. $\mathrm{Br}$ Med $\mathrm{J}$. 1992;304(6836):1215-1218.

89. Brown JB, Ramaiya K, Besancon S, et al. Use of medical services and medicines attributable to diabetes in Sub-Saharan Africa. PLoS One. 2014;9(9):e106716.

90. Basu A, Close CF, Jenkins D, Krentz AJ, Nattrass M, Wright AD. Persisting mortality in diabetic ketoacidosis. Diabet Med. 1993;10(3):282-284.

91. Kitabchi AE, Umpierrez GE, Murphy MB, et al. Management of hyperglycemic crises in patients with diabetes. Diabetes Care. 2001;24(1):131-153.

92. Graves EJ, Gillum BS. Detailed diagnoses and procedures, National HospitalDischarge Survey, 1994. National Center for Health Statistics. Vital Health Stat Series 13(127). 1997. Available from: https://www. cdc.gov/nchs/data/series/sr_13/sr13_127.pdf. Accessed June 1, 2016.

93. Naicker S. End-stage renal disease in sub-Saharan and South Africa. Kidney Int Suppl. 2003(83):S119-S122.

94. Diallo AD, Nochy D, Niamkey E, Yao Beda B. [Etiologic aspects of nephrotic syndrome in Black African adults in a hospital setting in Abidjan]. Bull Soc Pathol Exot. 1997;90(5):342-345.

95. Pastakia SD, Cheng SY, Kirui NK, Kamano JH. Dynamics, impact, and feasibility of self-monitoring of blood glucose in the rural, resource-constrained setting of western Kenya. Clin Diabetes. 2015;33(3):136-143.

96. Pastakia SD, Karwa R, Kahn CB, Nyabundi JS. The evolution of diabetes care in the rural, resource-constrained setting of western Kenya. Ann Pharmacother. 2011;45(6):721-726.

97. Mwai GW, Mburu G, Torpey K, Frost P, Ford N, Seeley J. Role and outcomes of community health workers in HIV care in sub-Saharan Africa: a systematic review. J Int AIDS Soc. 2013;16:18586.

98. Schneider H, Lehmann U. Lay health workers and HIV programmes: implications for health systems. AIDS Care. 2010;22(Suppl 1):60-67.

99. Chinenye S, Young EE. Diabetes conversation map in Nigeria: A new socioeducational tool in diabetes care. Indian J Endocrinol Metab. 2013;17(6):1009-1011.

100. Reaney M, Zorzo EG, Golay A, et al. Impact of Conversation Map ${ }^{\mathrm{TM}}$ education tools versus regular care on diabetes-related knowledge of people with type 2 diabetes: a randomized, controlled study. Diabetes Spectr. 2013:26(4):236-245.

101. Pastakia SD, Manyara SM, Kamano J, Menya D, Andama B, Laktabai J. Bridging income generation through the provision of incentives for care (BIGPIC). Poster presented at: American Diabetes Association Annual Meeting; June 2014; San Francisco, CA.

102. Institute for Health Metrics and Evaluation (IHME). Financing Global Health Visualization. Seattle, WA: IHME, University of Washington, 2016. Available from http://vizhub.healthdata.org/fgh/. Accessed September 1, 2015. 
Diabetes, Metabolic Syndrome and Obesity: Targets and Therapy

Diabetes, Metabolic Syndrome and Obesity: Targets and Therapy is an international, peer-reviewed open-access journal committed to the rapid publication of the latest laboratory and clinical findings in the fields of diabetes, metabolic syndrome and obesity research. Original research, review, case reports, hypothesis formation, expert opinion and commentaries are all considered for publication. The manuscript management system is completely online and includes a very quick and fair peer-review system, which is all easy to use. Visit http://www.dovepress.com/testimonials.php to read real quotes from published authors.

Submit your manuscript here: https://www.dovepress.com/diabetes-metabolic-syndrome-and-obesity-targets-and-therapy-journal 